\title{
CANADIAN NATURE FEDERATION
}

Many times in the last few years, as we gave protection to our birds of prey, developed a sanctuary for the prairie dog or tried to save some of our grassland or boreal forest, we have wished for the existence of a national body to help us in our efforts. Now, with the creation of the Canadian Nature Federation, we have the machinery for a strong national natural history organization.

Ideally there will be three levels in the natural history movement. Each community will have its local natural history society which can have regular meetings and develop various educational programs, including field trips. Such a group, large or small, will recognize the existence of problems and, if it needs help in solving them, should be able to seek consultation with both the provincial and national groups. In Saskatchewan the Saskatchewan Natural History Society is the intermediate group which attempts to publish informative articles and to acquaint people with problems which relate to the province. The Canadian Nature Federation is now the national group which will link all provincial groups and which should become an effective national voice.

The first president of this nation-wide group is Dr. Theodore Mosquin, Editor of Canadian Field Naturalist and botanist in the Canada Department of Agriculture. The organization has evolved from the Canadian Audubon Society which began in Toronto in 1948 but which became increasingly concerned with problems all across Canada. The constitution has now been revised to allow for a truly national society with directors respresenting every part of Canada. The magazine Canadian Audubon will not be published after the end of 1971 and the new, more substantial Nature Canada will make its first appearance early in 1972.

Dr. Jim Jowsey and I represented Saskatchewan at the inaugural meeting of the Canadian Nature Federation on September 18, 1971. We were impressed by the enthusiasm and optimism of the 403 people who registered. The meeting was similar in tone to that of our own annual meeting, friendly and very busy. There was an exhibition of the work of nature artists; there were reports, informative talks and films, field trips, a banquet and a special guest speaker (J. A. Livingston). This year the business part of the meeting included the presentation of letters patent which make the CNF a legal entity. The afternoon program included descriptions of problems from Sable Island in the east to Manning Park in the west to the Arctic in the north. The paper on the Arctic which was presented by Dalton Muir is printed in this issue of the Blue Jay to indicate the general concern of the meeting for environmental quality. Each annual meeting (next year's is to be held in Edmonton), along with the new magazine, should provide good factual information both for society members and for the general public, in the hope, of course, of arousing the latter to active involvement.

The national group will not charge provincial or local groups any affiliation fee. Instead, the organization will depend entirely on individual members who are interested in nature and anxious to support the cause of conservation. The regular membership fee of $\$ 6$ will go to the production of the magazine; additional amounts will be welcomed and acknowledged as donations. To publicize the new national group to SNHS members we invited CNF director Helen Lloyd of Winnipeg to speak at our annual meeting, October 16, 1971, in Moose Jaw. Following her talk it was agreed to send a $\$ 500$ donation to Canadian Nature Federation to help it get started. It is hoped that many individual members of SNHS will join the new society and urge their friends to join. Send cheques to Canadian Nature Federation, 46 Elgin Street, Ottawa, Canada KIP 5K6. Since CNF has just been organized, it is still untried and undeveloped but, designed as it is for the good of us all, it is our responsibility to make it work.

G. F. Ledingham. 